\title{
Effect of Direct Reduced Iron Proportion in Metallic Charge on Technological Parameters of EAF Steelmaking Process
}

\author{
Mohamed Abd Elkader*1, Ayman Fathy ${ }^{1}$, Mamdouh Eissa ${ }^{2}$, Sayed Shama* ${ }^{3}$ \\ ${ }^{1}$ Ezz Flat Steel, Suez, Egypt \\ ${ }^{2}$ CMRDI, Cairo \\ ${ }^{3}$ Faculty of Science, Benha University, Egypt
}

\begin{abstract}
The data obtained from industrial heats carried out in 185-ton electric arc furnace (EAF) were used to study the effect of direct reduced iron (DRI) percentage in metallic charge on the different steelmaking parameters and consumption figures. The present study carried out in a wide range of DRI percentage, 0- $90 \%$ of metallic charge, and the results have been statistically analyzed to correlate the percentage of DRI with the different consumption figures of electric energy, oxygen, coke and fluxing materials. In addition, the influence of DRI percentage on contents of tramp and detrimental elements affecting on steel quality has been also investigated. The results reveal improving the steel quality by increasing DRI percentage, as the tramp elements (Cu, Sn, Ni, Cr) and detrimental elements $(P, S)$ and also nitrogen, all decrease by increasing the percentage of DRI in the metallic charge. On the other hand, the increase in DRI percentage leads to increase in the consumptions (per ton of liquid steel) of electric energy, oxygen, coke and fluxing materials. Furthermore, the metallic yield decreases and the power on time and hence the tap-to-tap time increase as DRI percentage increases. With using higher DRI percentage in the charge, the yield strength and ultimate tensile strength of produced hot rolled bars of low carbon steel slightly decrease whereas elongation increases.
\end{abstract}

Keywords: Direct reduced iron, electric arc furnace, steel making parameters, mechanical properties

\section{Introduction}

Till the end of November 2013, about 1447 Mio tones steel was produced world-wide in 2013 [1]. The main task of most modern EAFs is to convert the solid raw materials to liquid crude steel as fast as possible and then refine further in subsequent secondary steelmaking processes [2]. Electric Arc Furnace (EAF) operations have improved significantly over the past 30 years. The most common raw-material in electric steelmaking is steel scrap. Due to shortage and availability of scrap, the use of direct reduced iron in EAF increased.

Very often, large amounts of ore based scrap substitute materials such as direct reduced iron (DRI) pellets, hot briquetted iron (HBI), iron carbide, etc. are used when producing steels with low residuals via EAF steelmaking. DRI is produced from a combination of pelletized and lump ore, which is reduced in a shaft furnace such as the Midrex furnace by reformed natural gas. The product DRI is therefore a pellet material with a large amount of internal porosity and a very low bulk density. Oxygen removal form iron ore creates lots of microscopic pores. These microscopic pores give the iron a sponge texture, therefore it is in another sense known as sponge iron [3] .

HBI is currently produced via two major process routes. By one process route, reduced DRI pellets can be fed from the reducing furnace into a briquetting machine. Physically compacting the pellets into larger briquettes greatly decreases the porosity of the material and increases the bulk density. HBI is also produced directly from ore fines via processes such as Finmet and Circored in which the ore fines are reduced in a series of fluidized bed reactors and then compacted into dense briquettes. Generally, the chemical properties of DRI and HBI sold commercially today are very similar. Nearly all commercial direct reduced materials contain between 80 to 90 percent metallic iron, 5 to 10 percent iron oxide, 5 to 10 percent gangue, and 0 to 4 percent carbon. The term gangue is used to describe the unreduced components of the mineral ore, including silica, alumina, lime, magnesia, etc. Due to the great similarities of DRI and HBI, this large group of materials will be referred to generally as DRI/HBI for most of this work [4] . Ezz Flat Steel (EFS) which located in Soukhna, Suez, Egypt has an annual capacity of 1.2 million tons of molten steel using scrap and direct reduced iron (DRI) as raw materials. One of the directions towards achieving high production and high quality steel was improvement in the chemical energy utilization system. Key features are as follows:

1) Electric arc furnace (EAF) of 185 tones tapping capacity equipped with 133 MVA transformers with three bottom porous plugs for argon purging and Eccentric Bottom Tapping (EBT). The EAF has three jet modules and one burner mounted on upper shell for oxygen, natural gas, and carbon injection.

2) A ladle furnace with a 28 MVA transformer and equipped with two bottom argon porous plugs and top wire feeders

3) A flexible thin slab caster to cast $70 \mathrm{~mm}$ slabs in wide range of casting speeds and steel grades

4) A hot strip mill connected to the this slab caster with tunnel type reheating and soaking furnace, slab descaling, roughing mill, transfer bar cropping and descaling, finishing mill (six 4-Hi stands with shifting and bending, equipped with crossing technology under 


\section{International Journal of Science and Research (IJSR) \\ ISSN (Online): 2319-7064 \\ Index Copernicus Value (2013): 6.14 | Impact Factor (2014): 5.611}

rolling load conditions), laminar cooling and coiling of strip.

5) Continuous casting machine with 6 strand, casting speed up to $4.5 \mathrm{~m} / \mathrm{min}$ and copper mold $130 * 130$ to produce steel billets from 8 up to 12 meter.

6) Two Bar mill with 18 stands to roll rebar from $10 \mathrm{~mm}$ up to $32 \mathrm{~mm}$ with 500000 ton/year capacity.

7) The present work deals with the effects of percentage of direct reduced iron in EAF charge mix on important steelmaking operation parameters for 4994 heats. The mechanical properties for some of them also investigated.

\section{Experimental Work}

\subsection{Practice of steelmaking with direct reduced iron and scrap}

After charging EAF by first bucket of scrap. The bucket contains light scrap, medium scrap and pig iron may be added. The average weight of scrap is changed in bucket from 20 to 110 ton according to steel grade will be produced. Melting of this bucket at temperature 1570-1590 ${ }^{\circ} \mathrm{C}$ for $15-20 \mathrm{~min}$ accompanied with oxygen injection, natural gas through burners to help in melting the scrap, slag building (lime and dolomite) added. After that The EAF charged by the second bucket of scrap which weight about 55-65 ton, melting takes place for 5-10 minutes. At the end of second bucket meltdown. Lime and dolomite added into EAF and/or DRI/HBI feeding takes place for 5-20 min. by weight 30-180 ton according to the charge mix, foaming the slag started and more slag building added. After that refining step takes place at $1600-1640^{\circ} \mathrm{C}$ by adding lime, deslagging step occurs. The final step is tapping the molten steel by about 180 ton at temperature $1645-1660{ }^{\circ} \mathrm{C}$.

\subsection{Practical Work}

The produced heats with different charge mix from $0 \%$ up to $90 \% \mathrm{DRI} / \mathrm{HBI}$ have been investigated. The last EAF sample chemical analysis, slag sample analysis, mechanical test results ,the recorded consumptions of coke, lime, total flux, oxygen, electrical energy, chemical energy and power on time, related to each heat charge mix were interpreted.

Impurities and residual elements in ferrous scrap samples while tables 4 and 5 show the average chemical composition of lime and EAF slag respectively. The average composition of, DRI, HBI used in this present investigation are given in tables 1 and 2 respectively where $\mathrm{Fe}_{\mathrm{M}}$ is metallic iron, $\mathrm{Fe}_{\mathrm{T}}$ is total iron. Table 3 for levels of impurities and residual elements in ferrous scrap samples while tables 4 and 5 show the average chemical composition of lime and EAF slag respectively.

Table 1: Average chemical composition of DRI, $\%$

\begin{tabular}{|c|c|c|c|c|c|c|}
\hline $\mathrm{Fe}_{\mathrm{M}}$ & $\mathrm{Fe}_{\mathrm{T}}$ & Metallization & gangue & $\mathrm{S}$ & $\mathrm{P}$ & $\mathrm{C}$ \\
\hline 84 & 90.4 & 92.9 & 5.24 & 0.006 & 0.03 & 1.3 \\
\hline
\end{tabular}

Table 2: Average chemical composition of HBI , \%

\begin{tabular}{|c|c|c|c|l|l|}
\hline $\mathrm{Fe}_{\mathrm{M}}$ & $\mathrm{Fe}_{\mathrm{T}}$ & Metallization & $\mathrm{S}$ & $\mathrm{P}$ & $\mathrm{C}$ \\
\hline 85.5 & 91.5 & 93.5 & 0.003 & 0.05 & 2.6 \\
\hline
\end{tabular}

Table 3: Impurities and residuals in scrap samples

\begin{tabular}{|c|c|c|c|c|c|c|}
\hline Sample & $\mathrm{P} \%$ & $\mathrm{~S} \%$ & $\mathrm{Cr} \%$ & $\mathrm{Ni} \%$ & $\mathrm{Cu} \%$ & $\mathrm{Sn} \%$ \\
\hline 1 & 0.014 & 0.051 & 0.118 & 0.159 & 0.55 & 0.018 \\
\hline 2 & 0.018 & 0.053 & 0.124 & 0.125 & 0.543 & 0.021 \\
\hline 3 & 0.026 & 0.047 & 0.168 & 0.15 & 0.518 & 0.018 \\
\hline 4 & 0.048 & 0.051 & 0.2 & 0.114 & 0.466 & 0.02 \\
\hline
\end{tabular}

Table 4: Average chemical composition of lime, $\%$

\begin{tabular}{|c|c|c|c|c|c|c|c|}
\hline $\mathrm{CaO}$ & $\mathrm{SiO}_{2}$ & $\mathrm{Fe}_{2} \mathrm{O}_{3}$ & $\mathrm{Mg} \mathrm{O}$ & $\mathrm{Al}_{2} \mathrm{O}_{3}$ & $\mathrm{P}_{2} \mathrm{O}_{5}$ & $\mathrm{TiO}_{2}$ & L.O.I \\
\hline 78 & 1.11 & 0.65 & 2.48 & 0.4 & 0.054 & 0.011 & 16.6 \\
\hline
\end{tabular}

Table 5: Average Chemical composition of investigated EAF slag, \%

\begin{tabular}{|c|c|c|c|c|c|c|}
\hline $\mathrm{CaO}$ & $\mathrm{SiO}_{2}$ & $\mathrm{Fe}_{2} \mathrm{O}_{3}$ & $\mathrm{MgO}$ & $\mathrm{Al}_{2} \mathrm{O}_{3}$ & $\mathrm{MnO}$ & $\mathrm{P}_{2} \mathrm{O}_{5}$ \\
\hline 34.97 & 18.77 & 24.53 & 24.53 & 8.4 & 2.37 & 0.57 \\
\hline
\end{tabular}

\section{Test Results and Discussion}

3.1 Effect of DRI/HBI ratio in charge mix on the detrimental and tramp elements in steel

\subsubsection{Sulfur and Phosphorous}

DRI/HBI is normally of high purity. Therefore, the source of residual metals like $\mathrm{Cu}, \mathrm{Ni}$ and $\mathrm{Cr}$, and of other elements as $\mathrm{P}$ and $\mathrm{S}$ in a bath of molten DRI/HBI and scrap is practically the scrap itself. Accordingly, an increase in $\mathrm{DRI} / \mathrm{HBI}$ in the metallic charge leads to a decrease in the concentrations of the above mentioned elements in the steel The effect of DRI/HBI ratio in the EAF charge on $\mathrm{S} \%$ in steel is shown in figure 1 . The sulfur content decreases from 0.0374 to $0.0266 \%$ when DRI/HBI \% in EAF charge mix increases from 0 to $80 \%$. The decrease in S mass $\%$ can be calculated from equation (1)

S mass $\%=0.03740-0.000135(\mathrm{DRI} / \mathrm{HBI}) \%(1)$

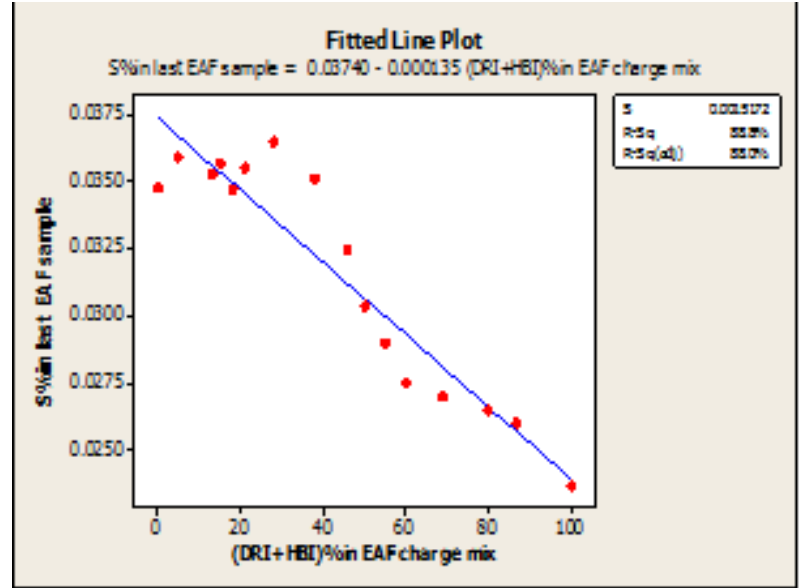

Figure 1: Effect of DRI/HBI on $\mathrm{S}$ mass $\%$ in $\mathrm{EAF}$

The $\mathrm{P} \%$ in last EAF sample decreased linearly from 0.01 to $0.004 \%$ when DRI/HBI \% in EAF charge mix increases from 0 to $80 \%$ as shown in figure 2 . The phosphorous in last EAF steel sample can be calculated by the following equation (2): 


\section{International Journal of Science and Research (IJSR) \\ ISSN (Online): 2319-7064}

Index Copernicus Value (2013): 6.14 | Impact Factor (2014): 5.611

$\mathrm{P} \%=0.01044+0.000039(\mathrm{DRI} / \mathrm{HBI})$

$\% 0.000001(\mathrm{DRI} / \mathrm{HBI}) \% * * 2(2)$

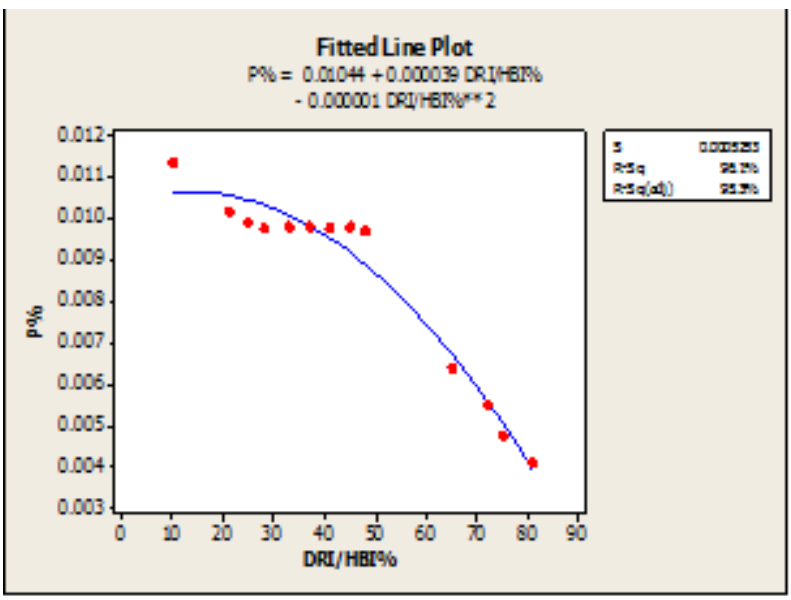

Figure 2: Variation of $\mathrm{P} \% \mathrm{VS}$. (DRI/HBI) \%

\subsubsection{Chromium and Nickel}

$\mathrm{Cr} \%$ in last EAF sample decreases linearly from 0.0530 to $0.0218 \%$ when DRI/HBI \% in EAF charge mix increases from 0 to $80 \%$ as shown in figure 3. The decrease in $\mathrm{Cr}$ mass $\%$ in the molten steel sample can be calculated by the following equation:

Cr mass $\%=0.05303-0.000390(\mathrm{DRI} / \mathrm{HBI}) \%(3)$

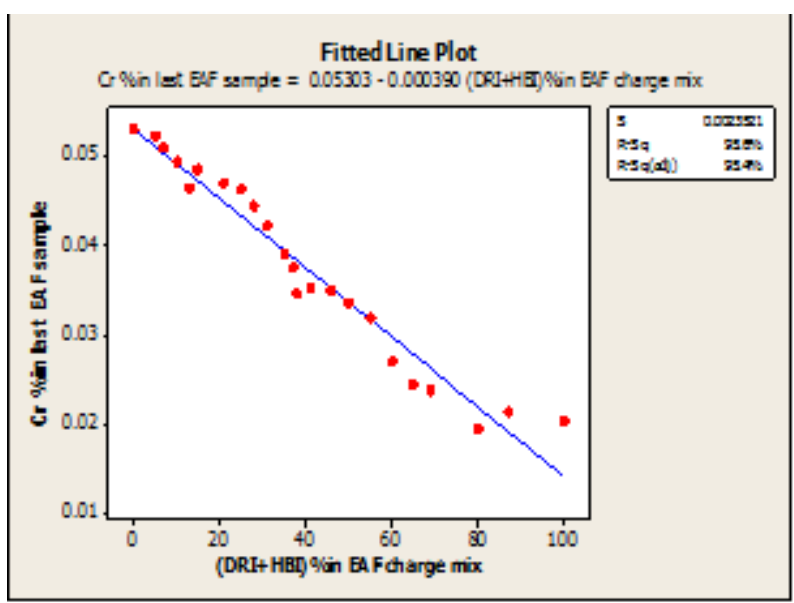

Figure 3: $\mathrm{Cr} \%$ versus (DRI/HBI) \%

$\mathrm{Ni} \%$ in last EAF sample decreases linearly from 0.073 to $0.0487 \%$ when DRI/HBI \% in EAF charge mix increases from 0 to $80 \%$ as shown in figure 4 . The decrease in $\mathrm{Ni}$ mass $\%$ in the molten steel sample can be calculated by the following equation:

Ni mass $\%=0.0729-0.000304(\mathrm{DRI} / \mathrm{HBI}) \%(4)$

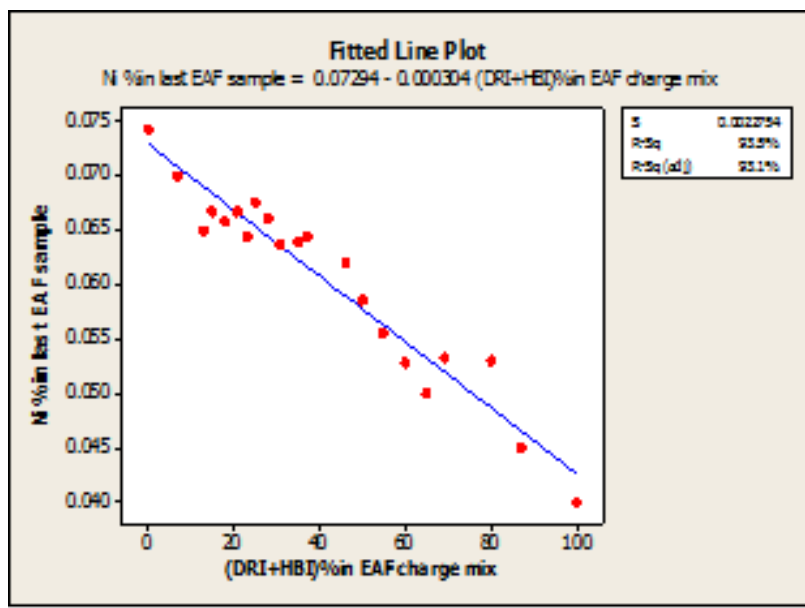

Figure 4: $\mathrm{Ni} \%$ vs. (DRI/HBI) \%

\subsubsection{Tin and copper}

Sn $\%$ in last EAF sample decreases from 0.038 to 0.01315 $\%$ when DRI/HBI \% in EAF charge mix increases from 0 to $80 \%$ as shown in figure 5 .

Sn $\%=0.01315-0.000064(\mathrm{DRI} / \mathrm{HBI}) \%(5)$

$\mathrm{Cu} \%$ in last EAF sample decreases from 0.1823 to 0.1501 $\%$ when DRI/HBI \% in EAF charge mix increases from 0 to $80 \%$ as shown in figure 6 . Copper in last steel sample can be calculated by the following equation

$\mathrm{Cu} \%=0.1823-0.000403$ (DRI/HBI) \% (6)

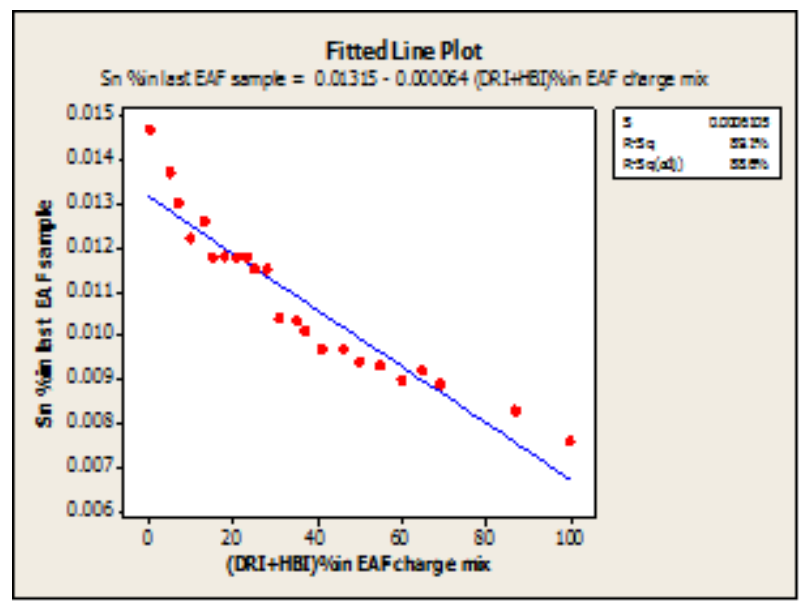

Figure 5: Tin \% versus (DRI/HBI) \%

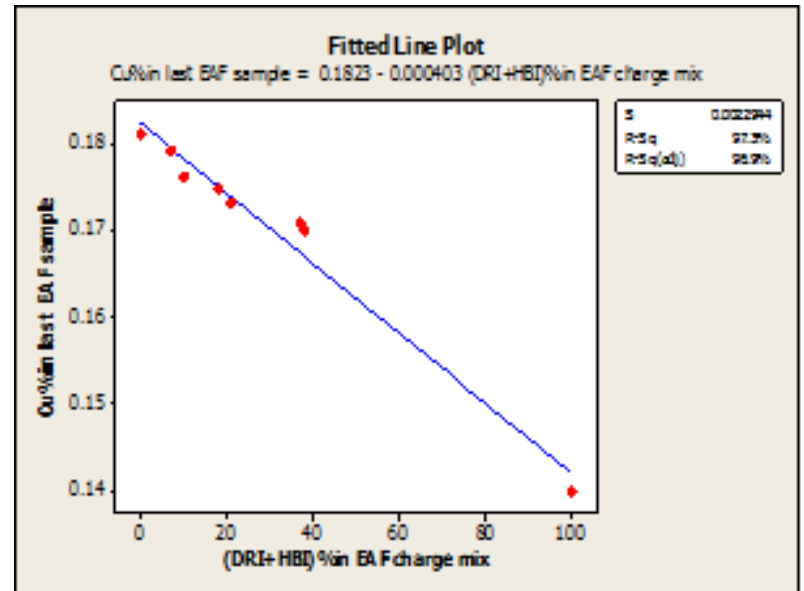

Figure 6: $\mathrm{Cu} \%$ vs. (DRI/HBI)\% 


\section{International Journal of Science and Research (IJSR) \\ ISSN (Online): 2319-7064 \\ Index Copernicus Value (2013): 6.14 | Impact Factor (2014): 5.611}

\subsubsection{Total residual elements}

Lime, $\mathrm{kg} / \mathrm{t}=40.20+0.2635(\mathrm{DRI} / \mathrm{HBI}) \%(8)$

Total tramp elements percentage $(\mathrm{Cr}+\mathrm{Ni}+\mathrm{Cu}+\mathrm{Sn}) \%$ in last EAF sample decreases linearly from 0.323 to $0.2286 \%$ when DRI/HBI \% in EAF charge mix increases from 0 to $80 \%$ as shown in figure 7 . The total tramp elements in final steel sample can be calculated by the following equation:

$$
(\mathrm{Cr}+\mathrm{Ni}+\mathrm{Cu}+\mathrm{Sn}) \%=0.3225-0.001174(\mathrm{DRI} / \mathrm{HBI}) \%
$$

For the production of high quality steel grades from scrap with varying quality and chemical composition, the compliance with high purity levels is sometimes only achieved with dilution of compliance with high purity levels is sometimes only achieved with dilution of unwanted tramp elements as $\mathrm{Pb}, \mathrm{Cu}, \mathrm{Cr}, \mathrm{Ni}, \mathrm{Mo}$, and $\mathrm{Sn}$ with highly pure substituting material direct reduced iron [5].

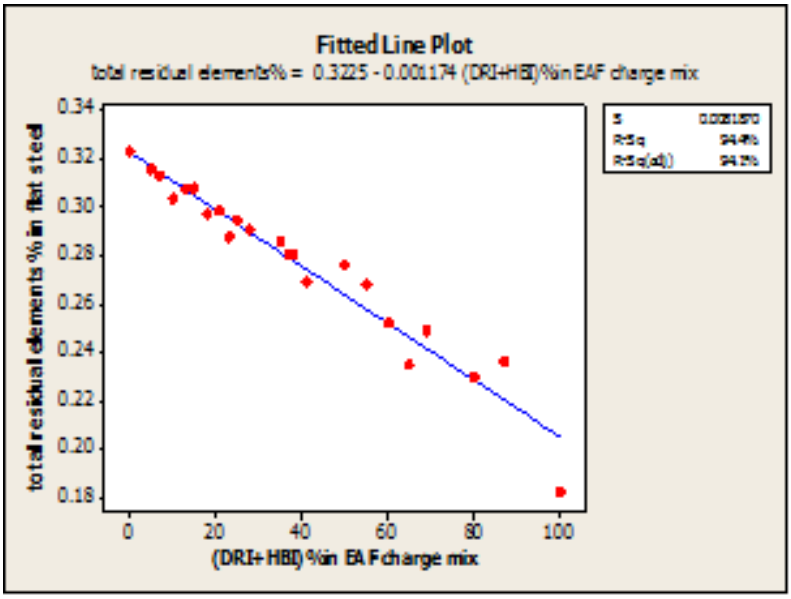

Figure7: Variation of total residual elements \% vs. (DRI/HBI) \%

\subsection{Effect of DRI/HBI ratio in charge mix on lime, total flux and EAF Slag quantity}

\subsubsection{Lime consumption}

$\mathrm{DRI} / \mathrm{HBI}$ usually contains silica as the main gangue constituent together with low levels of other impurities such as sulfur and phosphorus. According to the concentrations of these components in the DRI/HBI and the proportion of DRI/HBI in the metallic charge, varying quantities of lime must be fed into the furnace in order to slag the silica and remove the sulfur and phosphorus to the allowable levels of these elements for the grade of the steel to be produced.

Total lime consumption, $\mathrm{kg} / \mathrm{t}$ of tapped steel during EAF operation steps (melting, DRI feeding and refining) calculated and investigated versus variation of DRI/HBI \% in EAF charge mix. It is found that lime consumption increased from 40 to $60 \mathrm{~kg} /$ ton molten steel when DRI/HBI ratio increased from 0 to $80 \%$ in EAF charge mix as shown in figure 8 . The required lime for charge mix contains DRI/HBI can be calculated by the following equation:
According to equation (8) an increase of $10 \%$ in (DRI/HBI) ratio in charge mix leads to an increase in lime consumption by $2.6 \mathrm{~kg} / \mathrm{t}$ of liquid steel. This result is close to $2.5 \mathrm{~kg} / \mathrm{t}$ molten steel which obtained in previous study [6]

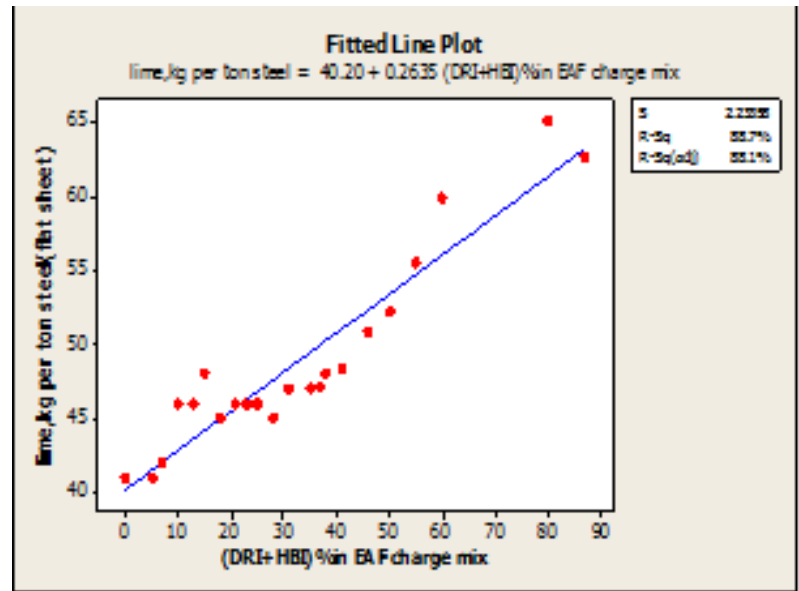

Figure 8: Lime consumption in EAF vs. (DRI/HBI)\%

\subsubsection{Total flux consumption}

The total flux (lime, dolomite and $\mathrm{MgO}$ ) consumption, $\mathrm{kg} / \mathrm{t}$ of tapped steel during EAF operation steps calculated and investigated versus variation of DRI/HBI \% in EAF charge mix and it is found that the total flux consumption increased from 66 to $85, \mathrm{~kg} / \mathrm{t}$ molten steel as DRI/HBI \% in EAF charge mix increased from 0 to $80 \%$ as shown in figure 9 . Total flux consumption, $\mathrm{kg}$ per ton can be calculated by equation (9):

Flux consumption, $\mathrm{kg} / \mathrm{t}=45.31+0.2416(\mathrm{DRI} / \mathrm{HBI}) \%$

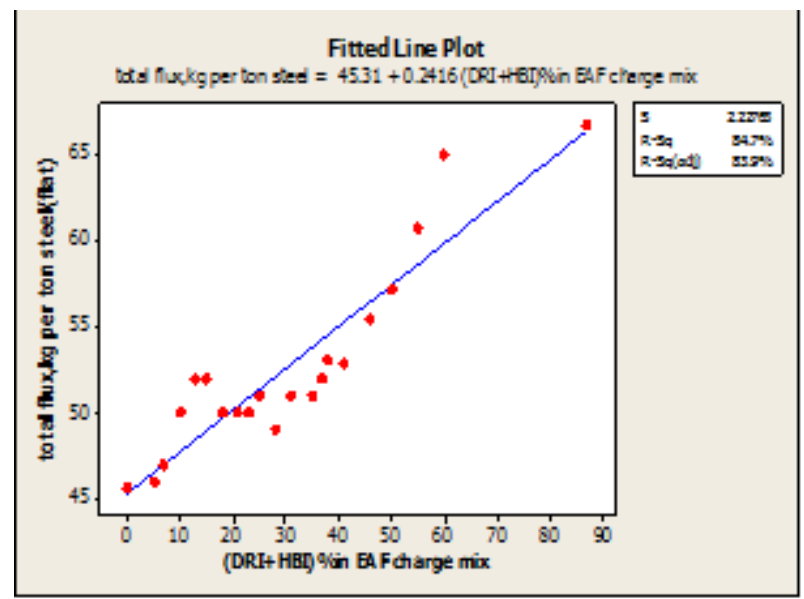

Figure 9: flux consumption in EAF vs. (DRI/HBI)\%

\subsubsection{Slag quantity and DRI /HBI percentage in EAF} charge mix

Slag quantity, $\mathrm{kg} / \mathrm{t}$ of liquid steel calculated as follows in equation (10) and investigated versus variation of DRI/HBI $\%$ in EAF charge mix, $0.95 \% \mathrm{CaO}$ in DRI/HBI, lime $78 \% \mathrm{CaO}$.

Slag quantity, $\mathrm{kg} / \mathrm{t}=$ (total lime, $\mathrm{Kg} * \mathrm{CaO} \%+\mathrm{EAF}$ dolomite, $\mathrm{Kg} * 0.6+0.95 * \mathrm{DRI}, \mathrm{Kg}) / \mathrm{CaO} \%$ in slag/liquid steel, $\mathrm{t}(10)$ 


\section{International Journal of Science and Research (IJSR) \\ ISSN (Online): 2319-7064 \\ Index Copernicus Value (2013): 6.14 | Impact Factor (2014): 5.611}

The variation of slag weight with (DRI/HBI) \%in EAF charge mix illustrated for 93 heats as in Figure 10 and may be given by the equation (11):

$$
\text { Slag quantity, } \mathrm{kg} / \mathrm{t}=127+2.437(\mathrm{DRI} / \mathrm{HBI}) \%
$$

It can be seen that $10 \%$ in (DRI/HBI) \%in EAF charge mix leads to increase in slag weight by $24.3 \mathrm{~kg}$. The slag weight depends mainly on the content and composition of the gangue in direct reduced iron and the basicity of the slag [6].so the slag weight increase as the DRI/HBI \% in EAF charge mix increases.

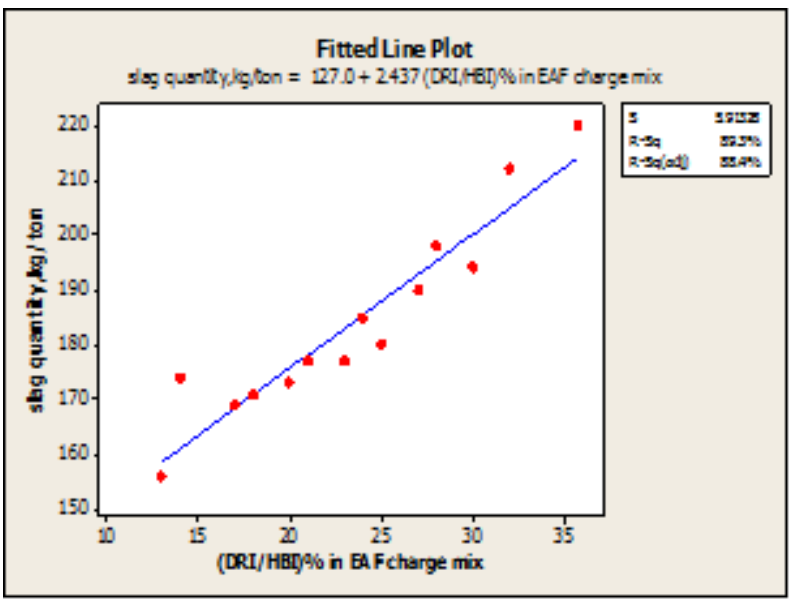

Figure 10: Slag quantity, $\mathrm{kg} / \mathrm{t}$ of steel vs.(DRI/HBI) \%

\subsection{Metallic yield and DRI /HBI percentage in EAF charge mix}

Metallic yield of tapped steel during EAF operation steps also calculated and investigated versus variation of DRI/HBI \% in EAF charge mix with $92.33 \%$ DRI/HBI average metallization. Figure 11 shows that EAF metallic yield decreased from 88.61 to $83.3 \%$ when DRI/HBI \%4in EAF charge mix increased from 0 to $80 \%$.Increasing of slag layer and hence metallic quantity will also decreased .The obtained regression equation (12) as follows:

Metallic yield \%=88.61 $-0.06641(\mathrm{DRI} / \mathrm{HBI}(12)$

\subsection{Electric consumption and DRI /HBI \% in EAF charge mix}

Electric power consumption, $\mathrm{kWh}$ per ton of tapped steel

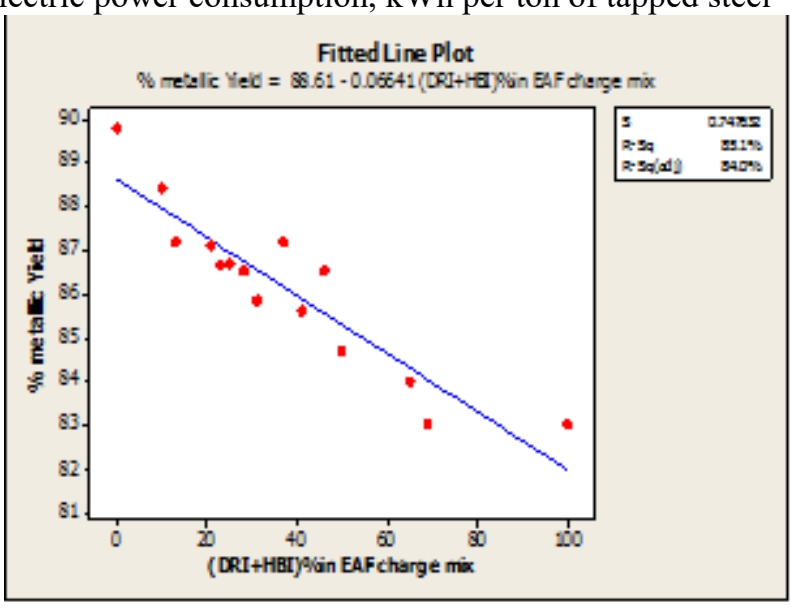

Figure 11:.Metallic yield vs. (DRI/HBI) \% during EAF operation steps also calculated and investigated with $93.2 \%$ DRI/HBI metallization versus variation of $\mathrm{DRI} / \mathrm{HBI} \%$ in EAF charge mix. It is found that electric power consumption increased from 384 to $500 \mathrm{kWh} / \mathrm{t}$ when $\mathrm{DRI} / \mathrm{HBI} \%$ in EAF charge mix increased from 0 to $80 \%$ as shown in Figure 12.The obtained regression equation (13) as follows

Electric consumption, $\mathrm{kWh} / \mathrm{t}=384.8+1.445(\mathrm{DRI} / \mathrm{HBI}) \%$

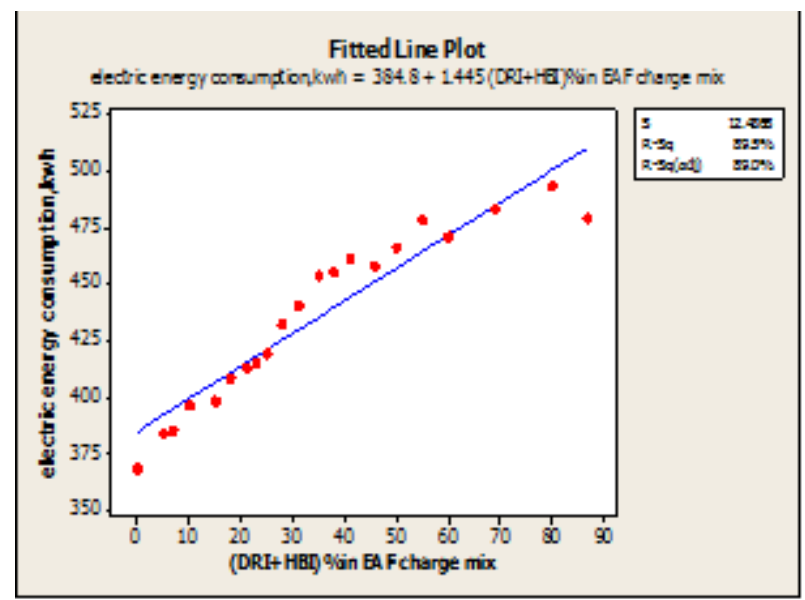

Figure 12: Electrical energy consumption vs.(DRI/HBI) \%

According to equation (13), an increase of $10 \%$ in (DRI/HBI) \% leads to an increase in electric power consumption by $14.5 \mathrm{kWh} / \mathrm{t}$ of liquid steel under the conditions of investigation. The electric energy consumption $384.8 \mathrm{kWh} / \mathrm{t}$ which close to the data published in previous study [5] $390 \mathrm{kWh} / \mathrm{t}$ at $0 \% \mathrm{DRI}$.

\subsection{Effect of DRI /HBI addition in EAF charge on power on time}

Power on time taken during EAF operation steps (melting DRI feeding and refining) and investigated versus variation of $\mathrm{DRI} / \mathrm{HBI} \%$ in EAF charge mix and it is found that power on time increased from 46 to 58 minutes when DRI/HBI \% in EAF charge mix increased from 0 to $85 \%$ as shown in Figure.13.The regression equation (14) as follows:

EAF power on time $=46.36+0.1320(\mathrm{DRI} / \mathrm{HBI}) \%(14)$

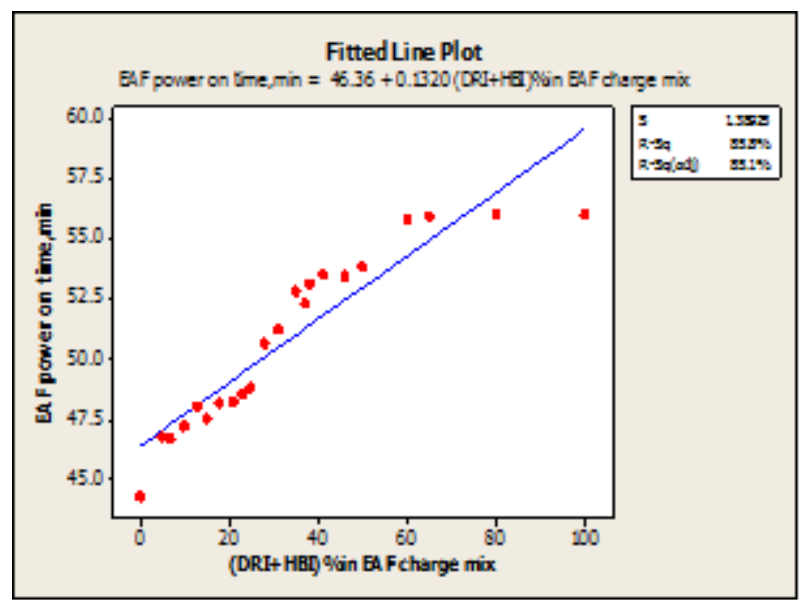

Figure 13: EAF power on time vs. (DRI/HBI)\% 


\section{International Journal of Science and Research (IJSR) \\ ISSN (Online): 2319-7064 \\ Index Copernicus Value (2013): 6.14 | Impact Factor (2014): 5.611}

The substitution of steel scrap with DRI increases the time needed for melting the EAF charge (Power-on time). This is attributed to the lower melting rate of DRI caused by the $\mathrm{FeO}$ that needs to be reduced. Moreover, having an acidic slag caused by the $\mathrm{SiO}_{2-}, \mathrm{Al}_{2} \mathrm{O}_{3}$-containing gangue materials in the DRI, it is also obvious that the specific consumption of lime and dolomite increases to manage the appropriate slag basicity near $x \mathrm{CaO} / \mathrm{xSiO}_{2}=2$. Due to the increasing slag masses by increasing the DRI in metallic charge, one need again longer melting time to bring the slag into solution and accordingly need more electrical energy consumption[5], and this also the reason for increasing lime, total flux consumption and then slag quantity.

\subsection{Total Carbon Consumption}

By investigating total carbon consumption in EAF operation versus variation of $\mathrm{DRI} / \mathrm{HBI} \%$ in EAF charge mix . It is found that carbon consumption increased from 8.7 to $17 \mathrm{~kg} / \mathrm{t}$ when (DRI/HBI) \% in EAF charge mix increased from 0 to $40 \%$ as shown in figure 14 . The obtained equation (15) as follows

Carbon consumption, $\mathrm{kg} / \mathrm{t}=8.673+0.2226$ (DRI/HBI) \% (15)

The obtained result $17 \mathrm{~kg} / \mathrm{t}$ Total carbon consumption at $40 \%$ of (DRI/HBI), matched with data published by Marcus Kirschen [5] $17 \mathrm{~kg} / \mathrm{t}$ for scrap based EAFs used in his investigation.

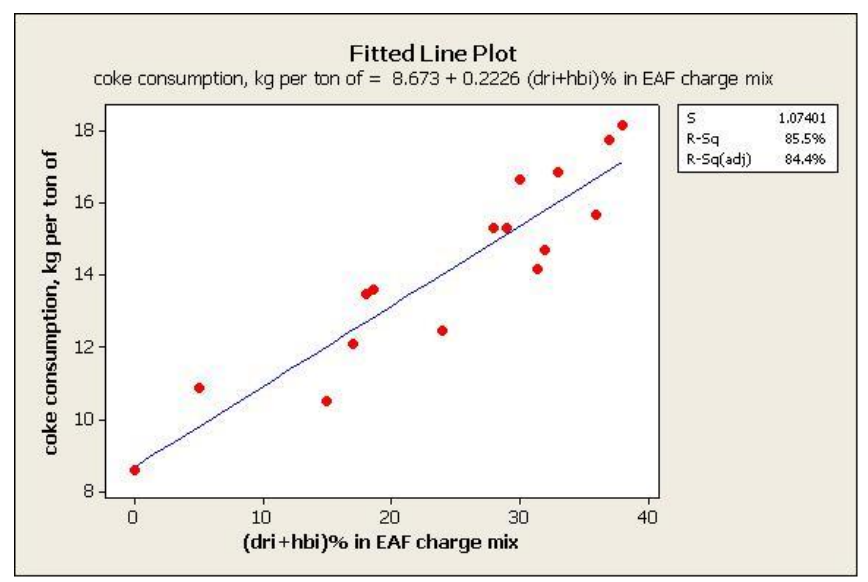

Figure 14: Total carbon vs. (DRI/HBI)\%

\subsection{Total oxygen consumption versus DRI /HBI ratio in EAF charge mix}

Oxygen consumption, $\mathrm{Nm}^{3}$ per ton of tapped steel during EAF operation steps (melting, DRI feeding and refining) calculated, investigated versus variation of $\mathrm{DRI} / \mathrm{HBI} \%$ in EAF charge mix and illustrated as in figure 15 and may be given by the equation (16)

Oxygen, $\mathrm{Nm}^{3} / \mathrm{t}=26.05-0.02884(\mathrm{DRI} / \mathrm{HBI}) \%$

$+0.001453(\mathrm{DRI} / \mathrm{HBI}) \% * * 2(16)$

It is seen that when DRI/HBI \% in EAF charge mix increases from 0 to $50 \%$, will result in increasing Oxygen consumption from 23.3 to $27.6 \mathrm{Nm}^{3} / \mathrm{t}$. Increasing DRI/HBI will result in increasing the combustible carbon which will require more oxygen. Figure 16 shows that the increase in DRI/HBI is accompanied by an increase in additional carbon and oxygen consumption; this can be explained as follows:

Increasing DRI/HBI results in an increase $\mathrm{FeO}$ in EAF bath which requires more additional carbon to be reduced to metallic iron and hence more oxygen for foamy slag in EAF process [5].

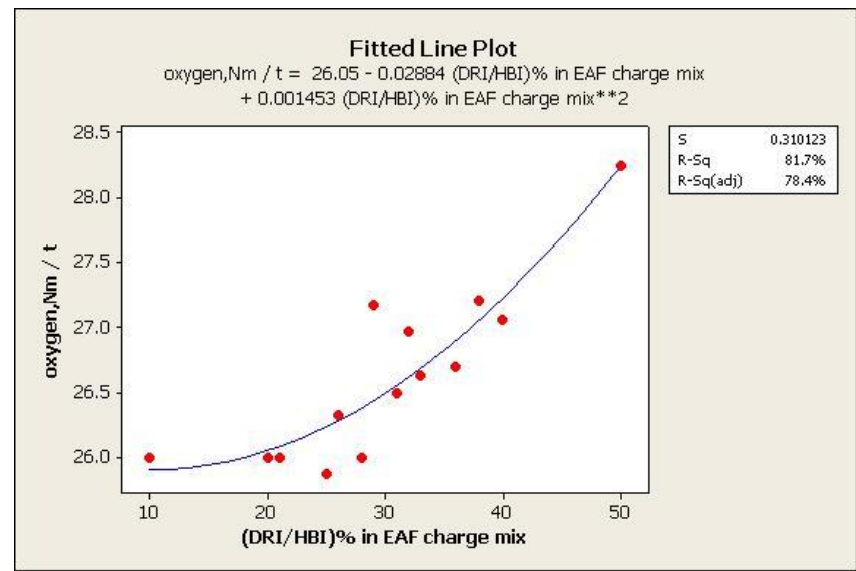

Figure 15: Oxygen consumption vs. (DRI/HBI)\%

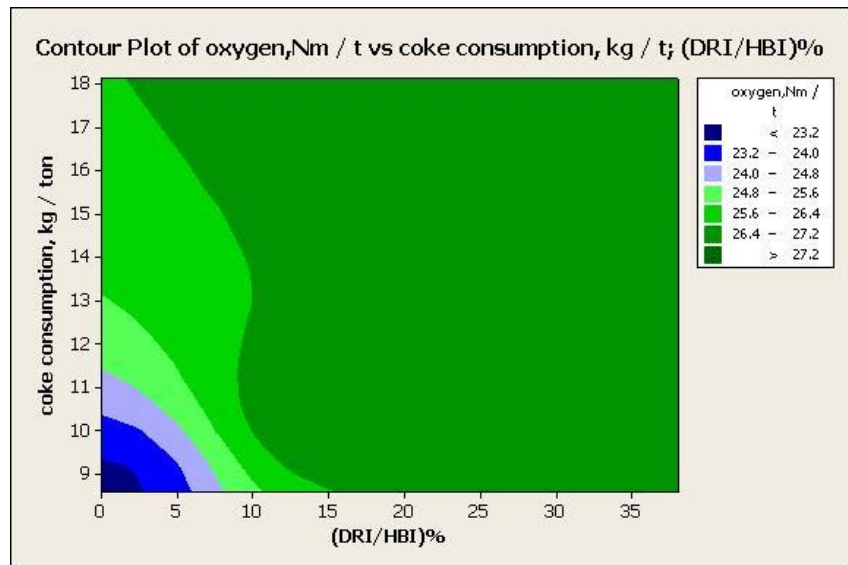

Figure 16: Counter plot of coke consumption vs. oxygen consumption and (DRI/HBI) \%

\subsection{Chemical energy and DRI /HBI ratio in EAF charge mix}

Oxygen injection is a common practice in steelmaking; it is used to control the concentration of dissolved carbon in liquid steel and simultaneously to generate heat due to exothermic reactions [9].

$\mathrm{C}+1 / 2 \mathrm{O} \rightarrow \mathrm{CO}+2.75 \mathrm{KWh} / \mathrm{Nm}^{3} \mathrm{O}_{2}$

$\mathrm{CO}+1 / 2 \mathrm{O} \rightarrow \mathrm{CO}_{2}+7 \mathrm{KWh} / \mathrm{Nm}^{3}$

$\mathrm{O}_{2} \mathrm{C}+\mathrm{O} 2 \rightarrow \mathrm{CO}_{2+} 4.88 \mathrm{KWh} / \mathrm{Nm}^{3} \mathrm{O}_{2}$

Other reactions in refining steps also produce chemical energy, Chemical energy produced for each heat during EAF operation steps is recorded and 


\section{International Journal of Science and Research (IJSR) \\ ISSN (Online): 2319-7064 \\ Index Copernicus Value (2013): 6.14 | Impact Factor (2014): 5.611}

calculated for ton of tapped steel and investigated versus variation of $\mathrm{DRI} / \mathrm{HBI} \%$ in EAF charge mix and it is found that chemical energy increased from 30 to 48.61 $\mathrm{kWh} / \mathrm{t}$ when DRI/HBI \% in EAF charge mix increased from 0 to $40 \%$ as shown in figure 18 . The obtained regression equation (17) as follows

\section{Chemical energy, $\mathrm{kWh} / \mathrm{t}=30.48+0.2282(\mathrm{DRI} / \mathrm{HBI}) \%$}

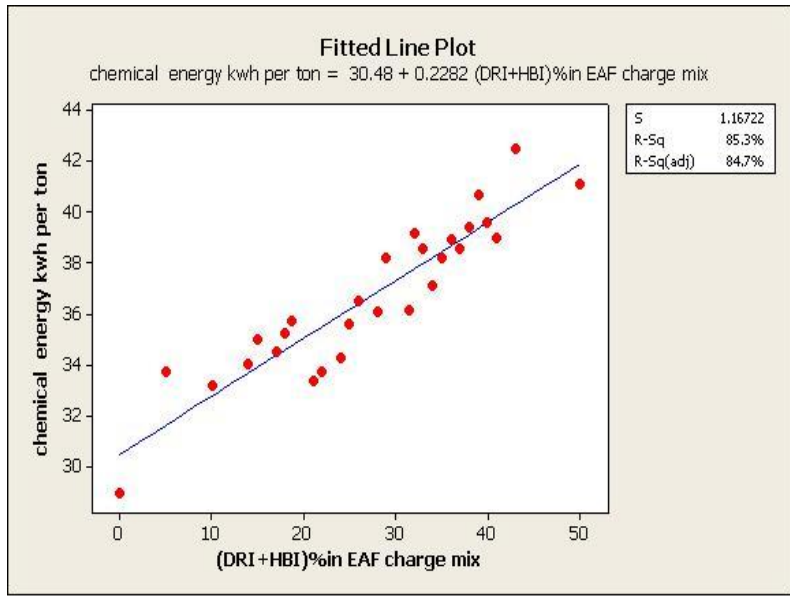

Figure 17: EAF chemical energy vs. (DRI/HBI) \%

It should be noted that the carbon produced in DRI (NG based) is usually more than the stoichiometric requirements needed to reduce the remaining portion of $\mathrm{FeO}$ in the product. DRI contains about $11 \mathrm{kgC} / \mathrm{tDRI}$. The excess carbon has significant impact on the $\mathrm{FeO}$ content of the slag and on the slag foaming that is required for an efficient EAF melting process. In case of negative excess carbon, the necessary addition of coal for $\mathrm{FeO}$ reduction is beneficial when late in the EAF process. However, not all the iron oxide is reduced into $\mathrm{Fe}$ since a portion of the $\mathrm{FeO}$ does always exist in the furnace slag. This means that the practical amount of excess carbon of DRI that is available for combustion in the steel bath, is more than the excess carbon calculated for DRI reduction. This term is called combustible carbon and defined as:

Combustible Carbon $=\mathrm{xC}$, DRI $-\mathrm{xC}$, stoichiometric (xFeO, DRI - xFeO, Slag) (18)

A second benefit obtained from the carbon in DRI is through the energetic benefits of $\mathrm{Fe}_{3} \mathrm{C} . \mathrm{Fe}_{3} \mathrm{C}$ yields energy through the exothermic reactions obtained during its dissociation in the steel bath, $-0.4 \mathrm{kWh} / \mathrm{kgC}$, in contrast to endothermic dissolution of carbon particles in the steel bath, $0.62 \mathrm{kWh} / \mathrm{kgC} \mathrm{[5].}$

Figure 19 shows increase DRI/HBI\% in EAF charge cause increase in carbon consumption $\mathrm{kg} / \mathrm{t}$ and consequently chemical energy increases this can be attributed to that increase in DRI/HBI in EAF charge mix results in increase additional carbon which required for reduction the more $\mathrm{FeO}$ comes from DRI/HBI and consequently chemical energy increases.

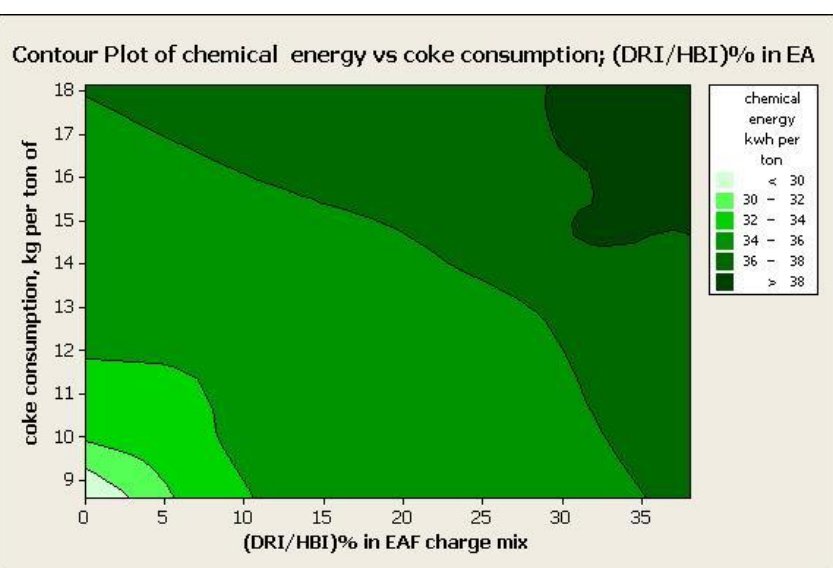

Figure 19: Carbon consumption, vs. chemical energy and (DRI/HBI) \%

\subsection{Natural gas consumption and DRI /HBI ratio in EAF charge mix}

Natural gas used with oxygen in EAF module burners which useful in scrap melting step.

Natural gas consumption, $\mathrm{Nm}^{3} / \mathrm{t}$ of tapped steel during melting EAF operation step calculated, investigated versus variation of $\mathrm{DRI} / \mathrm{HBI} \%$ in EAF charge mix and illustrated in figure 20 . It is shown that N.G consumption per ton of tapped steel $\mathrm{Nm}^{3} / \mathrm{t}$ decreased from 3.33to 1.7 when DRI/HBI \% in EAF charge mix increases from 0 to $80 \%$. The consumed natural gas can be calculated from equation 19 as follows:

$$
\text { N.G, } \mathrm{Nm}^{3} / \mathrm{t}=3.33-0.02043(\mathrm{DRI} / \mathrm{HBI}) \%
$$

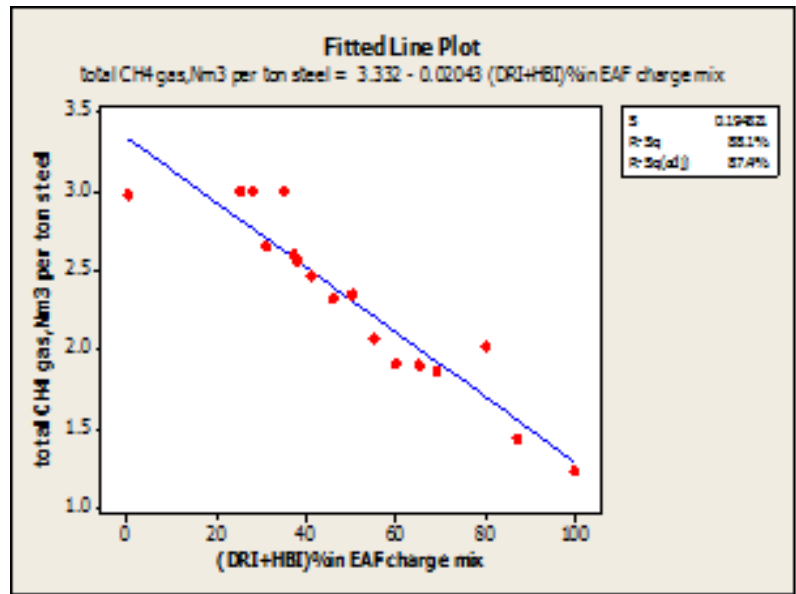

Figure 20: Natural gas consumption vs. (DRI/HBI) \%

\subsection{Nitrogen content and DRI/HBI \% in EAF charge mix}

Nitrogen content in EAF samples investigated versus variation of DRI/HBI \% in EAF charge mix and illustrated .It is found as a negative correlation which means decreasing in nitrogen content in EAF sample as DRI/HBI\% in EAF charge mix increases as shown in figure 21. Nitrogen content in EAF molten steel bath can be calculated from the following obtained regression equation (20) 


\section{International Journal of Science and Research (IJSR) \\ ISSN (Online): 2319-7064 \\ Index Copernicus Value (2013): 6.14 | Impact Factor (2014): 5.611}

The results agree with that obtained by Baosteel Group, Shanghai No. 5 Steel Co. Ltd. trial program. The results of the trials showed that nitrogen content decreased with increasing use of HBI [7], [8].

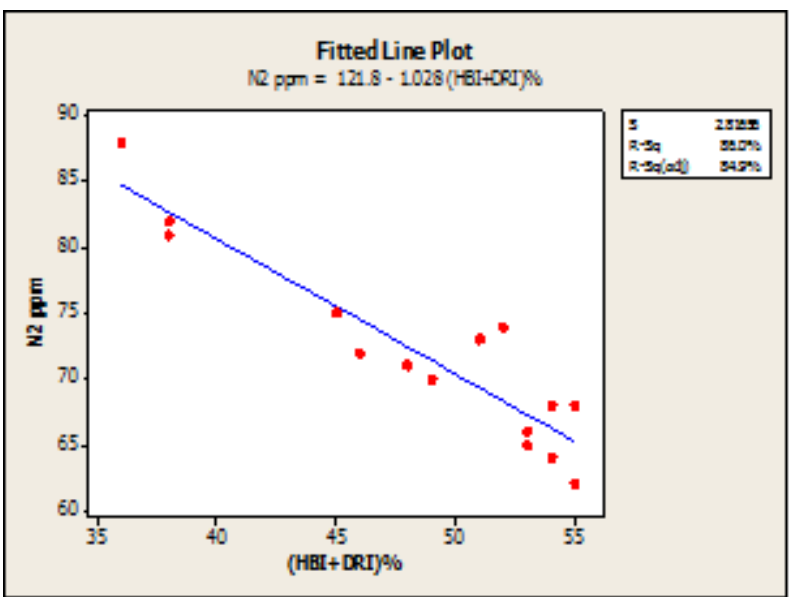

Figure 21: Nitrogen content in EAF vs. (DRI/HBI) \%

The reason for decreasing nitrogen is that the combustible carbon reacts with the oxygen injected to the melt in the $\mathrm{EAF}$, to release heat in the steel bath and also contribute $\mathrm{CO}$ gas in the slag foaming. With increasing combustible carbon in the EAF the nitrogen content of the tapped steel decreases.

Excess carbon from the DRI decreases the input of anthracite or injected graphite fines that is a major source for dissolved $\mathrm{N}$ in the $\operatorname{EAF}\left(0.1 \% \mathrm{~N}_{2}\right)$ besides infiltrated air [6].

\subsection{Mechanical properties of hot rolled low carbon steel and DRI percentage in EAF charge mix}

Tensile strength, yield strength and elongation percentage of $16 \mathrm{~mm}$ hot rolled low carbon steel rebar for 122 heats with variations from 13 to $33 \mathrm{DRI} / \mathrm{HBI} \%$ in EAF charge mix also investigated and it is found that as DRI/HBI \% increases, the Tensile strength and yield strength decreases while the elongation percentage increases as shown in figures22, 23 and 24 respectively. Regression equations (21), (22) and (23) for tensile strength, yield strength and elongation $\%$ are respectively

Tensile strength $\left(\mathrm{N} / \mathrm{mm}^{2}\right)=717.3-2.187(\mathrm{DRI} / \mathrm{HBI}) \%(21)$

Yield strength $\left(\mathrm{N} / \mathrm{mm}^{2}\right)=460.6-1.24(\mathrm{DRI} / \mathrm{HBI}) \%(22)$ Elongation $\%=16.06+0.1799(\mathrm{DRI} / \mathrm{HBI}) \%(23)$

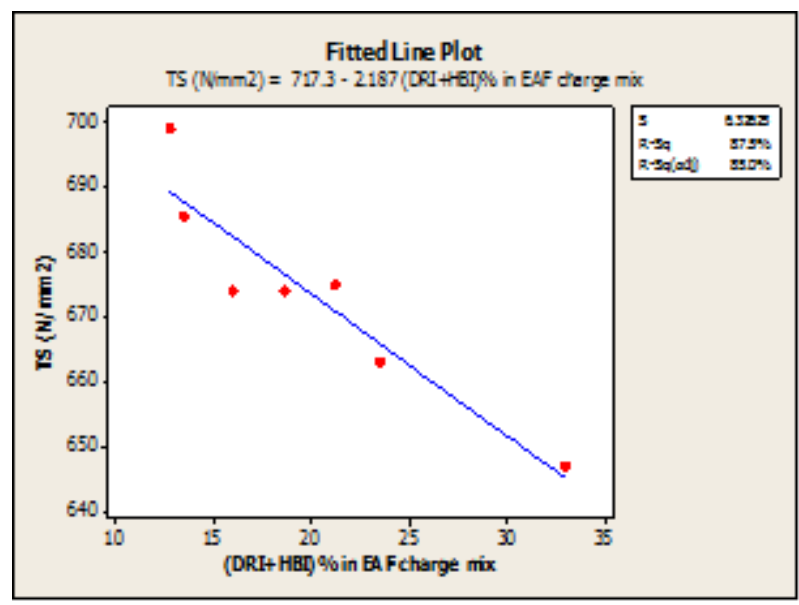

Figure 22: Tensile strength vs. (DRI/HBI)\%

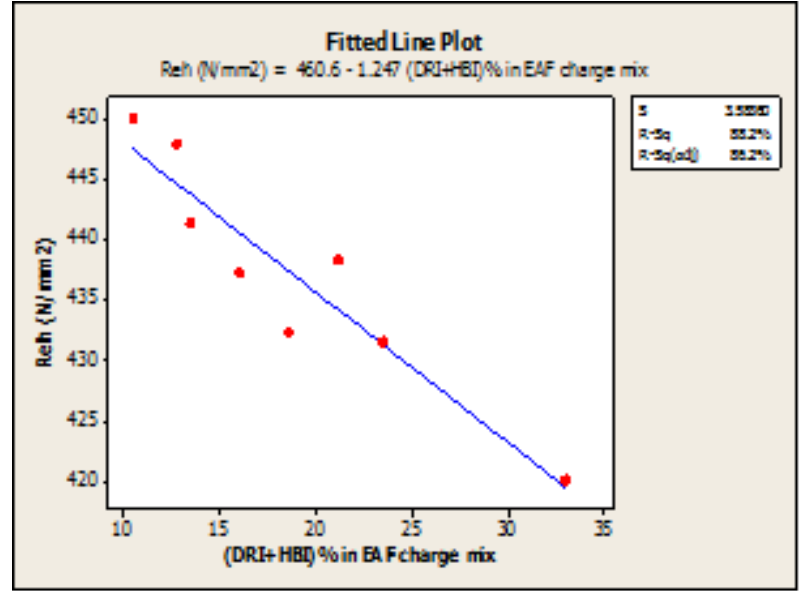

Figure 23: Yield strength vs. (DRI/HBI)\%

This matched results obtained by Shanghai No. 5 HBI Trial Results shows that using HBI provides an improvement in toughness, elongation, reduction in area, and strength [7].

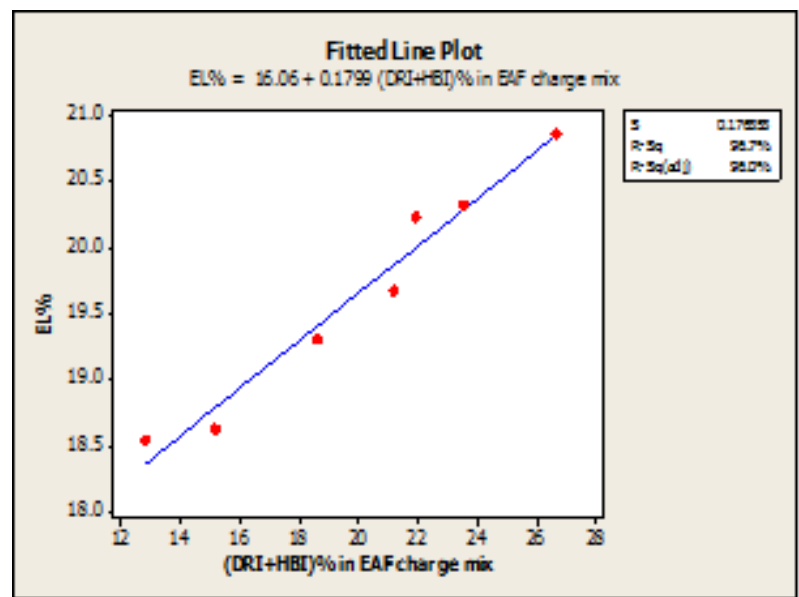

Figure 24: Elongation percentage vs. (DRI/HBI)\%

\footnotetext{
Abbreviations

Figure : Figure

$\mathrm{Kg} / \mathrm{t}$ : kilogram per ton of molten steel

$\mathrm{Nm} 3$ /t: cubic meter per ton of molten steel

N.G: natural gas

$\mathrm{Nm}^{3} / \mathrm{t}$ : gas consumption per ton of tapped steel min.: minutes
} 


\section{International Journal of Science and Research (IJSR) \\ ISSN (Online): 2319-7064}

Index Copernicus Value (2013): 6.14 | Impact Factor (2014): 5.611

$\mathrm{Wt} \%$ : weight percentage

$\mathrm{kgC/tDRI}$ : kilogram carbon per ton of DRI

TS:Tensile strength

(N/mm2):Newton per square millimeter

ReL : Lower yield strength

El: Elongation

\section{Conclusions}

The effects of varying the direct reduced iron percentage in the electric arc furnace charge mix on important technological parameters have been investigated on a 185 ton electric arc furnace. Regression equations have been obtained; the following conclusions can be made:

Advantages increasing direct reduced iron in EAF metallic charge as follows:

- Increasing percentage of DRI/HBI upon the bath residual metal level with medium quality scrap, decrease significantly the content of copper, which is frequently associated with hot rolling difficulties and rolling mill yield losses, is decreased significantly. Beside that the other residual elements such as $\mathrm{Ni}, \mathrm{Sn}$ and $\mathrm{Cr}$ decreases.

- Increasing DRI/HBI to scrap can also result in a significant decrease in the input to the melting furnace of refinable impurities such as sulphur and phosphorus.

- The consumption of natural gas per ton of liquid steel decreases as percentage of direct reduced iron in EAF charge mix increases.

- Chemical energy increases as percentage of direct reduced iron in EAF charge mix increases lowering contents of Nitrogen and hydrogen in steel bath.

- The yield point and the tensile strength decrease slightly, whereas the elongation increases with growing direct reduced iron proportion.

Disadvantages increasing direct reduced iron in EAF metallic charge as follows:

- Due to availability of scrap, direct reduced iron substitutes steel scrap but the increasing in DRI/HBI to scrap results in increasing the electrical power consumption beside consumptions of lime, fluxing material and carbon also.

- The consumptions per ton of liquid steel of electric power, lime, total flux, oxygen and total carbon increase with the sponge iron proportion of the charge.

- The metallic yield decreases with increasing direct reduced iron proportion.

- The slag weight per ton of steel, power on time and hence the tap-to-tap time of EAF increase with growing direct reduced iron proportion.

The positive and negative effects of using direct reduced iron on the steelmaking process require an optimization of both DRI/HBI in EAF Charge mix according to cost conditions.

Steel mills can benefit significantly from optimizing practices and logistics, increasing chemical energy use further and correctly using DRI/HBI percentage in EAF charge mix.

\section{Acknowledgement}

The authors are so grateful to EZZ FLAT STEEL Company for supporting this study.

\section{References}

[1] World steel association, steel production 2013

[2] M.Rahman, Fundamental Investigation of Slag/Carbon Interactions in Electric Arc Furnace Steelmaking, (2010)15-16.

[3] T. Ranjan Majhi, Modeling of Rotary Kiln for Sponge Iron Processing, Chapter1, (2012) 1-2

[4] Richard J. Fruehan and Christopher P. Manning, Final Report On Behavior of Phosphorus in DRI/HBI During Electric Furnace Steelmaking,AISI/DOE ,Technology Roadmap Program10, (2001)1,41-46.

[5] M. Kirschen, K. Badr, H. Pfeifer ,Influence of direct reduced iron on the energy balance of the electric arc furnace in steel industry, Energy 36(2011) 6146-6155

[6] M. Meraikib ,Effects of Sponge Iron on the Electric Arc Furnace Operation,ISIJ,vol.33,No.11, (1993), pp11741181

[7] D. Trotter,D. Varcoe,R. Reeves, ,"Use of DRI HBI in Control Nitrogen in Steel Products ,International Iron Mettalics Association,metallic.org.uk,(2002)13, Nitrogen Removal from Electric Arc Furnace Steel", Vol.78, No.8, (2007)588-594

[8] J. Pal, S.Ghosh, M. C.Goswami, D. P. Singh, Manoj Kumar ,R.K.Minj, A.K.Upadhyay, "Role of direct reduced Iron fines in steel products

[9] S. Hornby Anderson, Educated use of DRI/HBI improves eaf energy efficiency and yield and downstream operating results, 2002

\section{Author Profile}

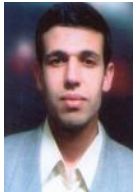

Mohamed Abdelkader Mohamed received the B.Sc and Diploma degree in Chemisty from Ain Shams Univeristy respectively 1994,2009. Works as lab supervisor in Central laboratory, Ezz Flat Steel Company from 2006 till now 